\title{
ASPECTOS PRELIMINARES ACERCA DA PROPOSTA DE UMA FILOSOFIA DA LIBERTAÇÃO EM AUGUSTO SALAZAR BONDY
}

\author{
Vivian Silva dos Santos ${ }^{1}$
}

RESUMO: O trabalho tem como proposta retomar a questão expressa pelo título do livro de Augusto Salazar Bondy, ¿Existe una filosofía de nuestra América? Nosso intento se mostra necessário na medida em que o objeto desta filosofia parece não estar por completo explicitado, mesmo porque; é comum encontrar autores que não consideram relevante se fazer tal pergunta, como é o caso de Enrique Dussel, que afirma ser esta uma questão superada. No entanto, o trabalho pretende apresentar tal pergunta como uma provocação dirigida a todos que pretendem produzir um pensamento filosófico original. Deste modo, é mister verificar se existe, segundo Salazar Bondy, uma maneira de fazer filosofia que é propriamente latinoamericana, ou, como o autor convencionou chamar, hispano-americana, bem como pensar se esta maneira pode ser, neste contexto, entendida como uma filosofia da libertação. 
ASPECTOS PRELIMINARES ACERCA DA PROPOSTA DE UMA FILOSOFIA DA LIBERTAÇÃO...

PALAVRAS-CHAVES: Enrique Dussel. Filosofia da Libertação. Salazar Bondy.

ABSTRACT: The paper aims to reposition the issue expressed by the very title of the book of Augusto Salazar Bondy, Is there a philosophy of our America?, a necessary regress to the extent that the object of this philosophy seems not to be fully explicit, even as it is common to find authors who do not consider this question relevant enough, as is the case of Enrique Dussel, who claims to be this issue completely outdated. However, the work intends to present this question as a provocation aimed at all who wish to produce an original philosophical thought. Thus, it is necessary to verify that, according to Salazar Bondy, there is a way of doing philosophy that is properly Latin American, or as the author prefered to call this thought, hispanicamerican, and we wonder if this hispanic-american philosophy of Salazar Bondy can be understood as a liberation philosophy.

KEYWORDS: Enrique Dussel. Liberation Philosophy. Salazar Bondy. 
Um dos livros mais relevantes sobre a discussão acerca da filosofia na América Latina, foi escrito em 1968 pelo peruano Augusto Salazar Bondy em uma década de grande efervescência política e cultural. O título do livro é bastante sugestivo, ¿Existe una filosofía de nuestra américa?. A referida obra trata da investigação sobre a existência de uma estrutura de pensamento genuinamente latino-americano e, sobretudo, procura saber até que ponto é relevante tomar esta questão como tema.

Para Salazar Bondy, é necessário ressaltar, a princípio, que as ideias propagadas no novo continente partem dos interesses de dominação espanhola, cujo duro núcleo de formação conceitual dizimou quase que por completo as tradições das populações indígenas. Sendo assim, só podemos falar de filosofia na América Latina a partir do ato de derrocada dos mitos e das lendas tradicionais.

El proceso del pensamiento filosófico hispanoamericano comienza con la introducción de las corrientes predominantes en la España de la época de la conquista, [...]. De este modo, los hispanoamericanos aprenden como primera filosofia, esto es, como primer modo de pensar en plan teórico universal, un sistema de ideas que responde a las motivaciones de los hombres de ultramar. (SALAZAR BONDY, 1975, p. 15) 
ASPECTOS PRELIMINARES ACERCA DA PROPOSTA DE UMA FILOSOFIA DA LIBERTAÇÃO...

Neste ínterim, os moradores deste Novo Mundo estão expostos aos modismos de produção intelectual propagados pelos colonizadores, com o agravante de as ideias propagadas já terem sido filtradas segundo critérios de seleção, esses que reforçam o que é melhor para manutenção do status quo. Resta-nos saber se tal produção é meramente uma imitação ou se existe algum aspecto de autenticidade em sua elaboração; entendendo-se por autenticidade, neste autor, o que foi assinalado no artigo de Vanderley Luiz Trindade; sobre o conceito de autenticidade e peculiaridade:

Tais conceitos se dão interconectados, porquanto uma filosofia de caráter original, tal como definimos acima, o é também autêntica, visto que um produto que resulta como uma criação nova não pode deixar também de ser autêntico no sentido de não ser falso, dominado pela ambigüidade. Por outro lado, uma filosofia de caráter autêntico possui um caráter original, pois um produto filosófico não falseado, nem equivocado não resulta como simples repetição de conteúdos doutrinários. (TRINDADE, 1998)

No capítulo "El Proceso" da obra citada, Salazar Bondy trata da produção acadêmica que é propagada na nossa América; produção que começa com a tarefa de comentar a obra dos filósofos apresentados pelos 
colonizadores - sendo que, tais comentários, até o século XVIII, são marcados por um tom de manutenção do poder político e religioso, acentuado pela Escolástica. Esse quadro começa a mudar com a introdução tardia de pensadores modernos: "Descartes, Leibniz, Locke, Hugo Grocio, así como Galileo y Newton, se cuentan entre los primeros autores difundidos entre nosotros y com efecto revolucionário en el processo intelectual, aunque el echo, medido com el reloj europeo, sea claramente tardio." ( SALAZAR BONDY, 1975, p.17).

Posteriormente há uma grande difusão das ideias positivistas, porém, já é possível destacar que há um movimento de crítica. Essas ideias passam a ser questionadas a fim de atribuir um novo sentido a elas. Levando-se em conta aspectos próprios da cultura dos países de nossa América, este grupo que procurou fazer a crítica ficou conhecido como "Os Fundadores"; eles também acentuaram os estudos acerca do conceito de duração em Henri Bergson como sobre a fenomenologia de Edmund Husserl e também a respeito do marxismo. Sobre esse coletivo de pensadores, Salazar Bondy diz que eles representam uma corrente bem definida do pensamento na Hispano-América e que contribuíram para que houvesse um aumento substancial de departamentos de filosofia neste continente, bem como a "normalização" do exercício filosófico e, com isso, surgisse a consciência "de los 
ASPECTOS PRELIMINARES ACERCA DA PROPOSTA DE UMA FILOSOFIA DA LIBERTAÇÃO...

problemas que afectam nuestro pensamiento, o por mejor decir, del problema radical de la justificación del filosofar hispano-americano." (SALAZAR BONDY, 1975, p. 27).

No Brasil, este processo de reelaboração das ideias positivistas surge no início do século XIX, nos últimos suspiros do período colonial, acompanhado da reforma pombalina que, por consequência, permitiu maior abertura às produções da modernidade europeia.

Pode-se constatar, no entanto, que na virada do século XIX ocorre uma inflexão nesta tradição positivista que, por assim dizer, se aprimora, se complexifica e se sofistica. Sem negar suas raízes, depura-se de algumas limitações e entraves: pode-se falar então, que ela passa a significar, no seu conjunto, um kantismo sem Kant ou um comtismo sem Comte, querendo-se dizer com isso que mantém os mesmos pressupostos até então defendidos a partir da intuição desses filósofos, mas livra-se de restrições e vínculos que, frente ao desenvolvimento do próprio saber científico, poderiam ser considerados anacrônicos. (SEVERINO, 2011, p.53)

Em muitos casos, a filosofia no Brasil é situada em meio às reações ocasionadas pelos vínculos com diferentes correntes de pensamento que acompanham as linhas 
neotomista, neopositivista, fenomenológica e dialética, essas que serão a base conceitual da discussão filosófica brasileira.

No que tange à tradição filosófica, Severino aponta, ainda, que seguimos modelos já constituídos assim como buscamos filosofar a partir de outros pensadores. No entanto, há produções que apresentam características de criatividade e criticidade, que sinalizam uma maior maturidade intelectual. "Sem dúvida, isto tem a ver com a própria tradição acadêmico-pedagógica de aprendizagem da filosofia, atravessada que sempre foi historicamente pelos complicadores oriundos de nossa dependência cultural [...]."(SEVERINO, 2011, p.22).

Em alguns momentos, é possível notar que Salazar assinala que características como criatividade e criticidade, ainda estão ausentes das produções intelectuais, as quais se encontram apoiadas em modelos preconcebidos, carecendo de uma metodologia que lhe sejam próprias. E, a fim de experimentar um novo aspecto da produção intelectual, Salazar volta suas pesquisas para seu ponto de origem, o Peru: "Los peruanos que sientem la necesidad de ser autênticos tienen ante sí el imperativo de librar su país de toda la dependencia que conlleve la sujeción a poderes extranjeros y, por tanto, alienacón de su ser." (SALAZAR BONDY, 1985, p. 37)

No que se refere à qualidade e ao alcance desses produtos intelectuais, fruto dos problemas que afetam a 
ASPECTOS PRELIMINARES ACERCA DA PROPOSTA DE UMA FILOSOFIA DA LIBERTAÇÃO...

nós, hispano-americanos, é preciso destacar, sobretudo, no que eles se diferenciam dos demais e, até então, são apresentados da seguinte forma:

- nota-se uma forte orientação do processo sociocultural;

- vinculação da filosofia com outras disciplinas, mas com um total distanciamento do estreito nexo com a criação científica;

- especialização e tecnicismo crescentes na produção;

- a influência de outras filosofias nacionais, e como ocorreu a recepção das filosofias europeias em nosso meio;

- sobre o conteúdo, percebe-se uma alternativa na orientação do pensamento, o que apresenta um caráter ondulatório da evolução filosófica hispano-americana, comparado a uma dialética no cerne deste modo de pensar, conciliando aspectos que em sua maioria são considerados diametralmente opostos, a este aspecto Salazar chama de "Evolução paralela com determinantes exógenos".

E, no cerne dessa recepção, há um paralelismo entre o desenvolvimento do pensamento europeu e o desenvolvimento ideológico hispano-americano, o que para nós aparece como etapas, cuja transição ocorre por 
intermédio de um pensamento que nos é estranho, pois é de fora para dentro e, por esse motivo tal recepção se mostra:

- descontínua, pois os sistemas não são internamente gerados;

- sinóptica, já que há uma abrupta introdução dos conteúdos, e um desenvolvimento truncado, em que estes pensamentos se nos apresenta de forma acabada, pois não tomamos parte de sua gestação;

- com retardo decrescente e aceleração crescente, posto que os produtos ideológicos por muito tempo nos chegaram tardiamente $\mathrm{e}$ agora, eles nos chegam quase que no instante de sua publicação.

Com isto, é gerada uma produção intelectual vernácula, que possui o caráter de uma transplantação de ideias, já que o pensar indígena não foi incorporado ao nosso processo filosófico, por isso fica claro que é muito mais comum que falemos mais de uma filosofia que foi trazida pelos colonizadores, do que de uma filosofia gerada em nosso próprio ambiente. Assim, a filosofia como prática da compreensão da realidade, na Hispano-América, é analisada segundo a filosofia europeia, o que reforça o sentido imitativo da reflexão- com importação das correntes de ideias, escolas, e sistemas totalmente definidos. 
ASPECTOS PRELIMINARES ACERCA DA PROPOSTA DE UMA FILOSOFIA DA LIBERTAÇÃO...

Segundo Salazar Bondy, isso reforça em nós uma espécie de receptividade universal, ou seja, estaríamos dispostos a receber todo tipo de material intelectual produzido pelos grandes centros da cultura ocidental, gerando superficialidade e pobreza, isentos de um estilo próprio de pensar, imersos em total ausência de originalidade e de uma tendência metodológica característica, o que aumentaria o sentimento de frustração intelectual e a distância entre quem pratica a filosofia e o conjunto do que é apresentado pela comunidade. Desse modo, não poderíamos falar de um selo nacional que explicite um modo de pensar característico, em que as comunidades se reconheçam nas filosofias difundidas. Pois, para ser original, a produção filosófica deveria traduzir a consciência de uma comunidade.

Mas o que interessa para Salazar Bondy; é saber sobre a qualidade, $\mathrm{o}$ alcance dos produtos intelectuais do continente hispano-americano e, sobretudo, o que os distingue. Então, procura investigar as várias repercussões da produção francesa, inglesa, alemã e, até mesmo italiana, indicando que a linha de análise destas influências ideológicas não é linear, mas ondulatória, pois seus desdobramentos aparecem ora tensos, ora afrouxados, em ritmos de defesa e apropriação alternados, o que pode imprimir um caráter dialético ao pensar hispanoamericano. 
Esta linha ondulante está paralelamente associada ao processo de desenvolvimento do pensamento ocidental e que, mesmo quando procuramos uma leitura que contextualize tal produção dentro da Hispano-América, estamos inexoravelmente diante de um corpo teórico que nos é estranho:

Se trata de lo siguiente: el desenvolvimiento ideológico hispanoamericano corre paralelo com el proceso del pensamiento europeo (y ahora también norteamericano) y los cambios que se producen en él coinciden estrechamente com las transformaciones de la filosofia occidental al estar determinadas en lo fundamental por estas. (SALAZAR BONDY, 1975; p. 36)

A partir desses apontamentos, o autor afirma ainda não ser possível falar de uma filosofia gerada no seio de nossa América. Para ele o que o que se fez até então foi uma “[...] narración del proceso de la filosofia europea en América hispanoindia [...]." (SALAZAR BONDY, 1975, p. 38) ou pode ser visto ainda como uma imitação da reflexão europeia. Embora o autor nos diga que a adoção das filosofias estrangeiras não se dá sem interferência dos que as adotam (estas que se mostram sujeitas a mudanças, recortes e ampliações na busca de um fim prático às mesmas), não deixa de ser implacável quando diz que "No hay pues, tal 
ASPECTOS PRELIMINARES ACERCA DA PROPOSTA DE UMA FILOSOFIA DA LIBERTAÇÃO...

sello, a menos que se quiera contar como caracter distintivo justamente la ausencia de definición [...]" (SALAZAR BONDY, 1975, p. 41). Mas precisamos pensar tais afirmações para além de sua literalidade espinhosa, pois elas possuem traços de uma conclamação pungente.

Foram apresentadas muitas críticas às afirmações feitas por Salazar Bondy em seu livro ¿Existe una filosofía de nuestra américa. Uma das críticas foi a do mexicano Leopoldo Zea, que também apresentou suas considerações no congresso de San Miguel. A fim de refutar as teses defendidas por Salazar Bondy, Zea apresentou seu artigo $L a$ filosofia americana como filosofia sin mas. Uma das refutações diz respeito à constatação feita por Bondy de que a filosofia na Hispanoamérica é inautêntica e imitativa, não sendo possível que de uma localidade subdesenvolvida possa surgir um pensamento original

Enrique Dussel também se mostra, em seu livro Filosofia da Libertação, contrário à tese inicial de Salazar, dizendo que "Para o autor Salazar Bondy, em sua obra ¿Existe una filosofía de nuestra américa?, a resposta era negativa: Não é possível filosofar dentro de uma situação como esta! Mas para nós, sim [...] (DUSSEL, 2005, p.31).

No entanto, basta um olhar mais atento para notar que Salazar apresenta suas teses com vistas à provocação, a qual instiga o debate. $\mathrm{O}$ livro é iniciado com a apresentação do objeto, depois as teses contrárias, as quais representam o 
caráter negativo para a formação de uma filosofia latinoamericana e, por fim, ele ilumina o debate com uma via de interpretação para o problema sugerido com o próprio título da obra. Assim, essa obra propõe uma volta à radicalidade, a fim de que nos lembremos da necessidade de se perguntar, tal como tantos filósofos o fizeram, "O que é isto, a filosofia?". Desse modo, o estudo da filosofia neste continente apresenta-se com uma necessidade de constante atualização e presentificação através desta questão fundamental, fazendo com que o filósofo, em sua reflexão, proponha soluções para problemas bem situados regionalmente.

A partir desse ponto, notamos um esforço empregado por Salazar Bondy para tirar os holofotes dos aspectos impeditivos de uma filosofia na nossa América, para se voltar aos argumentos que sustentam a possibilidade de um tipo específico de pensamento. Essa perspectiva é afirmada quando comenta José Gaos: "Que siendo esto así, la obra de los hispanoamericanos no haya sido valorada se debe a que los pueblos hegemónicos, las grandes potencias mundiales, con su influencia política determinan los reconocimientos y estimas en filosofía [...]" (SALAZAR BONDY, 1973, p. 81).

Assim, mesmo que Salazar escreva que o modo americano de se pensar reside em uma espécie de ajuste, “[...] un ajuste de los productos ideologicos del pensamiento mundial a nuestras circunstancias" (SALAZAR BONDY, 
ASPECTOS PRELIMINARES ACERCA DA PROPOSTA DE UMA FILOSOFIA DA LIBERTAÇÃO...

1973; p. 95), tais ajustes não podem ser configurados como mera aceitação, como se fôssemos apenas um receptáculo da produção europeia. É preciso abrir uma nova via de análise que parta dos problemas fundamentais de nossos povos e se assente na reflexão sobre a realidade da América. Assim, "Se verá más clara la significación de este elemento desenvolviendo lo positivo y soperando lo limitado [...], que aborda el problema de nuestra filosofía desde la perspectiva de la situación social global, de nuestros países[...].” (SALAZAR BONDY, 1973, p. 111).

Todavia, mesmo assinalando que um dos traços marcantes do modo de pensar "hispanoamericano" está calcado no subdesenvolvimento e na dependência, estes devem ser superados. Dessa superação, surgirá uma filosofia autêntica, que caminha para a destruição dos laços que a detêm dominada para, com isto, “[...]ser una conciencia canceladora de prejuicios, mitos, idolos, una conciencia apta para develar nuestra sujeción como pueblos[...]; en consecuencia, una conciencia liberadora[...].”(SALAZAR BONDY, 1973, p. 126).

Assim, é possível notar que, ao iniciar sua reflexão com a apresentação dos aspectos impeditivos para um pensar filosófico autêntico na América Latina, principalmente para que possamos nos perceber como dominados e subdesenvolvidos, Salazar Bondy fornece alguns fundamentos para se pensar uma filosofia da 
libertação, pois, para se libertar é necessário, de antemão, perceber-se acossado.

Então, depreendemos que, no movimento interno do texto, há uma estrutura dialética, esta parece se configurar também no modo como autor entende esse processo de elaboração da filosofia hispanoamericana, tratando de revelar que, na contramão, enquanto se constitui uma consciência da dominação, ainda é possível encontrar o germe da libertação do pensar para que seja possível criar uma filosofia autêntica.

Com isto, afirma-se que já havia, em seu livro ¿Existe una filosofía de nuestra américa?, uma filosofia da libertação em Salazar Bondy. Isso, se a entendermos de forma embrionária, que, em conformidade com o modo como Dussel a define, consiste em "[...]descobrir o fato opressivo da dominação, em que os sujeitos se constituem senhores de outros sujeitos[...]." (DUSSEL, 1993; p.18).

$\mathrm{O}$ que vai ao encontro do que Salazar afirma no final de seu livro: "La constituición de un pensamiento genuino y original y su normal desenvolvimiento no podrán alcanzarse sin que se produzca una decisiva transformación de nuestra sociedad mediante la cancelación del subdesarrollo y la dominación." (SALAZAR BONDY, 1973, p.131). E é definitivamente corroborado na afirmativa de que "[...] hay todavia posibilidad de liberación y, en la medida que la hay, estamos obligados a optar por una línea 
ASPECTOS PRELIMINARES ACERCA DA PROPOSTA DE UMA FILOSOFIA DA LIBERTAÇ̃̃O...

de acción que materialize esa posibilidad y evite su frustración." (SALAZAR BONDY, 1973; p. 133).

Então, Salazar Bondy coloca, como a principal tarefa dos pensadores da Hispanoamérica, partirem de uma filosofia que se mostra autêntica, na medida em que se afirma na diferença, o que é, inegavelmente, a marca de uma filosofia da libertação.

\section{NOTAS}

1 Mestranda em Filosofia pela Universidade Federal de São Paulo (UNIFESP). Professora da Educação Básica/Filosofia (Secretaria da Educação do Estado de São Paulo). E-mail: vivian8z@yahoo.com.br. 


\section{REFERÊNCIAS BIBLIOGRÁFICAS}

DUSSEL, Enrique. Filosofia da libertação: crítica à ideologia da exclusão. 3. ed. Trad. Georges Maissiat. São Paulo: Paulus, 2005.

. 1492: O encobrimento do outro - a origem do mito da modernidade. Trad. Jaime A. Clasen. Petrópolis: Vozes, 1993.

SALAZAR BONDY, Augusto Salazar. Entre Escila $y$ Caribdis. Lima: Rickchay Perú, 1985.

- ¿Existe una filosofía de nuestra américa?. 3. ed. México D.F.: Siglo Vientiuno Editores, 1975.

SEVERINO, Antônio Joaquim. Filosofia contemporânea no Brasil: conhecimento, política e educação. 6. ed. Petrópolis, RJ: Vozes, 2011.

TRINDADE, Vanderlei Luiz. O debate entre Salazar Bondy e Leopoldo Zea. Revista Digital Livre Filosofar, v. 3, n. 4, 1998. Disponível em <http://www.ifil.org/Biblioteca/ trindade.htm>. Acesso em 15 de março de 2014.

ZEA, Leopoldo. Ensayos sobre filosofía de la historia. México: Stylo, 1953. In: BONDY, Augusto Salazar. ¿Existe una filosofía de nuestra américa?. 3. ed. México D.F.: Siglo Vientiuno Editores, 1975. 